\title{
Effects of propofol-based total intravenous anesthesia on gastric cancer: a retrospective study
}

This article was published in the following Dove Press journal:

OncoTargets and Therapy

\author{
Xiaoyu Zheng' \\ Yu Wang' \\ Linlin Dong' \\ Su Zhao ${ }^{2}$ \\ Liping Wang' \\ Hong Chen' \\ Yang $X u^{\prime}$ \\ Guonian Wang' \\ 'Department of Anesthesiology, \\ Harbin Medical University Cancer \\ Hospital, Harbin, China; ${ }^{2}$ Department \\ of Thoracic Surgery, Harbin Medical \\ University Cancer Hospital, Harbin, \\ China
}

Background: Several kinds of cancer surgeries with propofol-based total intravenous anesthesia (TIVA) have been shown to have better outcomes than those with sevoflurane-based inhalational anesthesia (INHA). However, the effects of this anesthetic technique have not been investigated in patients with gastric cancer. In this study, the authors retrospectively examined the link between the choice of anesthetic technique and overall survival in patients undergoing gastric cancer resection.

Methods: We conducted a retrospective analysis of the database of all patients undergoing gastric cancer resection for gastric cancer between 2007 and 2012. Patients who received TIVA or INHA were administered patient-controlled intravenous analgesia for 72-120 hours postoperatively. Survival was estimated using the Kaplan-Meier log-rank test, and associations between anesthetic technique and outcomes were analyzed using Cox proportional hazards regressions after propensity matching.

Results: A total of 2,856 anesthetics using INHA or TIVA were delivered in the study period. After propensity matching, 897 patients remained in each group. According to Kaplan-Meier analysis, the use of TIVA was associated with improved survival $(P<0.001)$. TIVA was associated with a hazard ratio (HR) of 0.67 (95\% confidence interval [CI]: 0.58-0.77) for death in univariate analysis and 0.65 (95\% CI: $0.56-0.75)$ after a multivariate analysis of known confounders in the matched group. Cancer stage (HR $=0.74,95 \% \mathrm{CI}: 0.64-0.86, P<0.001)$ and degree of differentiation ( $\mathrm{HR}=1.28,95 \% \mathrm{CI}$ : $1.11-1.47, P<0.001$ ) were also associated with survival in the univariate analysis in the matched group. In the multivariable Cox model, cancer stage (HR $=0.72,95 \% \mathrm{CI}: 0.62-0.84, P<0.001)$ and degree of differentiation $(\mathrm{HR}=1.23$, 95\% CI: $1.07-1.42, P<0.001)$ were associated with survival in the matched group.

Conclusion: These results indicate that TIVA may be associated with improved survival in gastric cancer patients who undergo resection.

Keywords: anesthesia, propofol, sevoflurane, patient-controlled analgesia, gastric cancer, overall survival

\section{Introduction}

Gastric cancer is the second most common cause of global cancer mortality, and surgical removal of tumors remains a mainstay in the course of treatment. ${ }^{1}$ Although surgical excision of primary or even metastatic tumors can save or extend life, it has long been acknowledged that the surgery itself may precipitate or accelerate tumor recurrence. ${ }^{2}$ Surgery induces increased shedding of cancer cells into blood circulation, ${ }^{3}$ suppresses antitumor immunity allowing circulating cells to survive, ${ }^{4,5}$ upregulates adhesion molecules in target organs, recruits immune cells capable of entrapping tumor 
cells, and induces changes in the target tissue. ${ }^{6,7}$ Moreover, it has been well established that surgery can cause selective suppression of T-helper-1 (Th1) function and a shift toward a T-helper-2 (Th2) cytokine pattern with cell-mediated immune suppression..$^{8-11}$ In addition to these changes directly related to surgical treatment, there are countless perioperative variables that can alter the oncological outcomes, including anesthetic management, blood transfusion, the development of hypothermia, and the evolution of postoperative complications.

It has recently been demonstrated that propofol could exert antitumor properties through several kinds of mechanisms, including the suppression of survival capability, tumor progression, and the invasion of cancer cells. ${ }^{12-15}$ Moreover, propofol also stimulates the activation and differentiation of T-helper lymphocytes, a key step in anti-infective and antitumor immune responses. ${ }^{16-18}$ In contrast, sevoflurane exhibited immunosuppression and tumorigenesis through a number of mechanisms, including suppression of natural killer (NK) cell activity and lymphocyte function, which induce proliferation, apoptosis, and invasion of cancer cells. ${ }^{16,19-21}$ These results lead to the hypothesis that propofol-based total intravenous anesthesia (TIVA) may provide survival advantages compared with sevoflurane-based inhalational anesthesia (INHA). However, the effect of propofol-based TIVA on the outcome of gastric cancer resection has not been previously evaluated in the clinical setting. Therefore, we conducted a retrospective analysis of electronic records to make a comparison of overall survival in patients after gastric cancer resection, between propofol-based TIVA and sevoflurane-based INHA.

\section{Methods}

\section{Ethics statement}

This retrospective observational study complied with the guidelines of the Declaration of Helsinki, and was approved by the Ethics Committee of Harbin Medical University Cancer Hospital. As this study involved a retrospective review of existing data as well as medical records, and all individual information was securely protected by delinking identifying information from the main data set and was available only to investigators, the Institutional Review Board of Harbin Medical University Cancer Hospital approved this study and specifically waived the need for written informed consents. Consent was waived because this study was part of an audit, conformed to standards for minimal risk research, and did not affect patient safety or clinical care. Moreover, all of the data were analyzed anonymously.

\section{Patient selection}

After approval was received from the Ethics Committee of the Harbin Medical University Cancer Hospital, 2,856 gastric cancer cases were identified from the medical records of patients admitted to the hospital for gastric cancer resection between 2007 and 2012. We excluded patients who had metastasis, emergency operations, and/or laparoscopic procedures. Patients who experienced anesthesia and analgesia consistent with the following standard and postoperative pathologies of gastric cancer were included. Medical records for all of the included patients were obtained.

\section{Anesthesia technique and grouping method}

In both groups, anesthesia was induced with midazolam $0.05-0.15 \mathrm{mg} / \mathrm{kg}, 0.5 \mu \mathrm{g} / \mathrm{kg}$ fentanyl, and $1-2.5 \mathrm{mg} / \mathrm{kg}$ propofol. Patients were allocated into TIVA and INHA groups by the different anesthetic techniques used. In the TIVA group, anesthesia was maintained with propofol infusion and remifentanil. In the INHA group, anesthesia was maintained with sevoflurane and remifentanil infusion. Patients received patient-controlled intravenous analgesia with $3 \mu \mathrm{g} / \mathrm{mL}$ fentanyl or $0.5 \mu \mathrm{g} / \mathrm{mL}$ sufentanil for $72-120$ hours postoperatively in both groups.

\section{Data collection}

The status of patients up to March 31, 2015 was determined from medical records, and the causes of death were recorded. The following information was obtained: demographic data, cancer stage, American Society of Anesthesiologists (ASA) grade, duration of surgery, degree of differentiation, transfusion, preoperative or postoperative adjuvant chemotherapy, and/or radiation therapy. Cancer stage was assessed based on the 7 th edition of the American Joint Committee on Cancer Cancer Staging Manual. The degrees of differentiation included well differentiated, moderately differentiated, poorly differentiated, and other/unknown differentiated. Survival time was measured from the date of gastrectomy to death or to the last follow-up time before March 31, 2015.

\section{Statistical approach}

All statistical analyses were performed using SPSS17.0 (IBM; Armonk, NY, USA). To account for differences in baseline characteristics, propensity scores were obtained by using binary logistic regression using all the patients' demographics presented in Table 1. Matching was performed 
Table I Correlation between two types of anesthesia and clinicopathological features in gastric cancer patients

\begin{tabular}{|c|c|c|c|c|c|c|}
\hline \multirow[t]{3}{*}{ Variables } & \multicolumn{3}{|c|}{ Overall patients } & \multicolumn{3}{|c|}{ Matched patients } \\
\hline & \multirow{2}{*}{$\begin{array}{l}\text { TIVA } \\
(n=I, 506)\end{array}$} & \multirow{2}{*}{$\begin{array}{l}\text { INHA } \\
(n=I, 350)\end{array}$} & \multirow[t]{2}{*}{$P$-value } & \multirow{2}{*}{$\begin{array}{l}\text { TIVA } \\
(n=897)\end{array}$} & \multirow{2}{*}{$\begin{array}{l}\text { INHA } \\
(n=897)\end{array}$} & \multirow[t]{2}{*}{$P$-value } \\
\hline & & & & & & \\
\hline Age (years) & & & 0.174 & & & 1.000 \\
\hline$<60$ & $868(57.6 \%)$ & $744(55.1 \%)$ & & $516(57.5 \%)$ & $516(57.5 \%)$ & \\
\hline$\geq 60$ & $638(42.4 \%)$ & $606(44.9 \%)$ & & $381(42.5 \%)$ & 381 (42.5\%) & \\
\hline BMI $\left(\mathrm{kg} / \mathrm{m}^{2}\right)$ & & & 0.099 & & & 0.708 \\
\hline$<20$ & $359(23.8 \%)$ & $358(26.5 \%)$ & & $235(26.2 \%)$ & $242(27.0 \%)$ & \\
\hline$\geq 20$ & I, 147 (76.2\%) & $992(73.5 \%)$ & & $662(73.8 \%)$ & $655(73.0 \%)$ & \\
\hline \multicolumn{2}{|c|}{ Duration of surgery (hours) } & & 0.593 & & & 0.962 \\
\hline$<3.5$ & $825(54.8 \%)$ & $753(55.8 \%)$ & & $505(56.3 \%)$ & $504(56.2 \%)$ & \\
\hline$\geq 3.5$ & 681 (45.2\%) & $597(44.2 \%)$ & & $392(43.7 \%)$ & $393(43.8 \%)$ & \\
\hline Gender & & & 0.083 & & & 0.951 \\
\hline Female & I, 193 (79.2\%) & $\mathrm{I}, 033(76.5 \%)$ & & $738(82.3 \%)$ & 737 (82.2\%) & \\
\hline Male & $313(20.8 \%)$ & $317(23.5 \%)$ & & $159(17.7 \%)$ & $160(17.8 \%)$ & \\
\hline Smoking & & & 0.131 & & & 0.925 \\
\hline No & $726(48.2 \%)$ & $689(51.0 \%)$ & & $442(49.3 \%)$ & $440(49.1 \%)$ & \\
\hline Yes & $780(51.8 \%)$ & $661(49.0 \%)$ & & $455(50.7 \%)$ & $457(50.9 \%)$ & \\
\hline Alcoholism & & & 0.474 & & & 0.925 \\
\hline No & $810(53.8 \%)$ & 708 (52.4\%) & & $463(51.6 \%)$ & $465(51.8 \%)$ & \\
\hline Yes & $696(46.2 \%)$ & $642(47.6 \%)$ & & $434(48.4 \%)$ & $432(48.2 \%)$ & \\
\hline Hypertension & & & 0.063 & & & 0.785 \\
\hline No & $1,360(90.3 \%)$ & I, $190(88.1 \%)$ & & $830(92.5 \%)$ & $833(92.9 \%)$ & \\
\hline Yes & 146 (9.7\%) & $160(11.9 \%)$ & & 67 (7.5\%) & 64 (7.1\%) & \\
\hline \multicolumn{2}{|c|}{ Ischemic cardiomyopathy } & & 0.969 & & & 0.515 \\
\hline No & I,4l4 (93.9\%) & $1,268(93.9 \%)$ & & $864(96.3 \%)$ & $869(96.9 \%)$ & \\
\hline Yes & $92(6.1 \%)$ & $82(6.1 \%)$ & & $33(3.7 \%)$ & $28(3.1 \%)$ & \\
\hline Diabetes & & & 0.174 & & & 0.790 \\
\hline No & I,438 (95.5\%) & $1,274(94.4 \%)$ & & $869(96.9 \%)$ & $867(96.7 \%)$ & \\
\hline Yes & 68 (4.5\%) & $76(5.6 \%)$ & & $28(3.1 \%)$ & $30(3.3 \%)$ & \\
\hline ASA & & & 0.566 & & & 0.963 \\
\hline I & $204(\mid 3.5 \%)$ & $199(14.7 \%)$ & & 91 (10.1\%) & 89 (9.9\%) & \\
\hline ॥ & I, 197 (79.5\%) & I,065 (78.9\%) & & $770(85.8 \%)$ & $770(85.8 \%)$ & \\
\hline III & $105(7.0 \%)$ & $86(6.4 \%)$ & & $36(4.0 \%)$ & $38(4.2 \%)$ & \\
\hline Cancer stage & & & 0.860 & & & 0.849 \\
\hline Lower (I-II) & $844(56.0 \%)$ & $76 \mathrm{I}(56.4 \%)$ & & 499 (55.6\%) & $503(56.1 \%)$ & \\
\hline Higher (III) & $662(44.0 \%)$ & 589 (43.6\%) & & 398 (44.4\%) & 394 (43.9\%) & \\
\hline Tumor differenti & & & 0.632 & & & 0.919 \\
\hline Lower (I) & $563(37.4 \%)$ & 493 (36.5\%) & & $283(31.5 \%)$ & $28 \mathrm{I}(3 \mathrm{I} .3 \%)$ & \\
\hline Higher $(2-4)$ & $943(62.6 \%)$ & 857 (63.5\%) & & $614(68.5 \%)$ & $616(68.7 \%)$ & \\
\hline
\end{tabular}

Notes: Detected by Pearson's $\chi^{2}$ tests. Degrees of differentiation: degree I, poorly differentiated; degree 2, moderately differentiated; degree 3 , well differentiated; degree 4, other/unknown differentiated. Cancer stages: stage I: TI, N0, M0/T2, N0, MO/TI, NI, M0; stage II: T3, N0, M0/T4a, NI, M0/T3, NI, M0/T2, N2, M0/TI, N3, M0; stage III: T2, $\mathrm{N} 3, \mathrm{MO} / \mathrm{T} 3, \mathrm{~N} 2, \mathrm{MO} / \mathrm{T} 3, \mathrm{~N} 3, \mathrm{M0} / \mathrm{T} 4 \mathrm{a}, \mathrm{N} 2, \mathrm{MO} / \mathrm{T} 4 \mathrm{a}, \mathrm{N} 3, \mathrm{MO} / \mathrm{any} \mathrm{T} 4 \mathrm{~b}$, any N, M0; stage IV: any T, any N, MI.

Abbreviations: ASA, American Society of Anesthesiologists; BMI, body mass index; INHA, inhalational anesthesia; TIVA, total intravenous anesthesia.

using Greedy $5 \rightarrow 1$ Digit Match algorithm. ${ }^{22}$ The correlation between the two groups of anesthesia (TIVA and INHA) and the pathologic features of patients were analyzed with the $\chi^{2}$ test. Survival curves were obtained using the Kaplan-Meier method, and statistical analysis was performed using the log-rank test. A Cox proportional hazards regression model was performed for univariate and multivariate survival analyses. A value of $P<0.05$ was considered statistically significant.

\section{Results}

\section{Patient characteristics}

Using the inclusion and exclusion criteria described earlier, we identified a cohort of 2,856 patients (Figure 1), 52.7\% of whom $(n=1,506)$ were in the TIVA group, and $47.3 \%$ of whom $(n=1,350)$ were in the INHA group. The median follow-up times for the TIVA and the INHA groups were 43.6 months and 39.7 months, respectively. The groups exhibited no differences in age, height, weight, duration of 


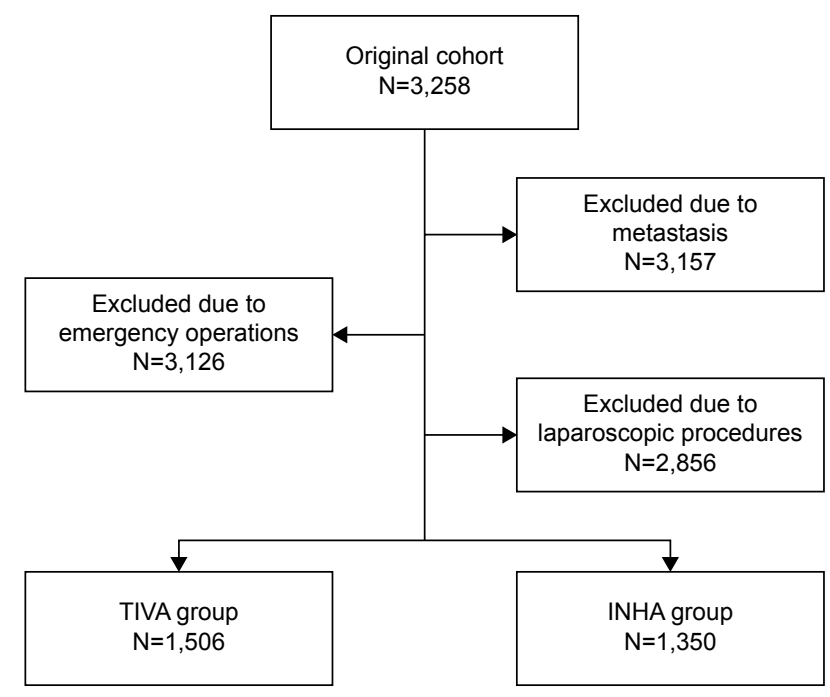

Figure I Patient identification and exclusion.

Abbreviations: INHA, inhalational anesthesia; TIVA, total intravenous anesthesia.

surgery, gender, smoking history, alcoholism, hypertension history, ischemic cardiomyopathy, diabetes, and ASA grade after surgery. Moreover, no differences in cancer stage or degree of differentiation were observed between the two groups (Table 1).

\section{Association between TIVA use and overall survival}

The mean survival time in the TIVA and INHA groups were 49.1 months and 40.6 months, respectively. In a log-rank test, perioperative TIVA use was associated with overall survival $(P<0.001)$, with an estimated hazard ratio (HR) of 0.63 (95\% confidence interval [CI]: $0.56-0.70)$ in the univariate analysis (Table 2). Cancer stage (HR $=0.64$, 95\% CI: $0.57-0.72, P<0.001)$, degree of differentiation (HR $=1.20,95 \%$ CI: $1.07-1.35, P<0.001)$, and blood transfusion ( $\mathrm{HR}=1.18,95 \% \mathrm{CI}: 1.02-1.37, P=0.027$ ) were also associated with overall survival. However, chemotherapy
$(\mathrm{HR}=0.90,95 \% \mathrm{CI}: 0.80-1.01, P=0.062)$ and age $(\mathrm{HR}=0.99$, 95\% CI: $0.88-1.11, P=0.883$ ) were not found to be associated with survival. In the multivariate Cox model that considered only the statistical effect of TIVA use (Model 1, Table 3), cancer stage and degree of differentiation were associated with TIVA use, which exhibited an adjusted estimated HR of 0.61 (95\% CI: $0.55-0.69, P<0.001)$. In the multivariate Cox model, cancer stage (HR $=0.62,95 \%$ CI: $0.55-0.70$, $P<0.001$ ), degree of differentiation ( $\mathrm{HR}=1.17,95 \% \mathrm{CI}$ : 1.04-1.31, $P<0.001$ ), and blood transfusion ( $\mathrm{HR}=1.26$, 95\% CI: $1.09-1.47, P=0.002)$ were associated with survival. Kaplan-Meier estimates of survival as a function of postoperative time for the two groups are provided in Figure 2 . The resulting curves differed significantly $(P<0.001$, log-rank test).

\section{Propensity-matched analysis}

Propensity-matched analysis resulted in 897 patients in each group, with similar baseline characteristics. TIVA was still associated with a reduced $\mathrm{HR}$ in both univariate $(\mathrm{HR}=0.67$, 95\% CI: 0.58-0.77) and multivariable ( $\mathrm{HR}=0.65,95 \% \mathrm{CI}$ : $0.56-0.75)$ analyses. The association of other variables with outcome was similarly unaffected.

\section{Discussion}

This retrospective analysis of 2,856 patients who underwent gastric cancer resection evaluated overall survival in patients receiving sevoflurane-based INHA compared with TIVA using propofol and remifentanil. After propensity matching and adjustment for known confounding factors, our results seem to suggest an early and sustained beneficial effect of TIVA on tumor-related mortality after gastric cancer compared with sevoflurane-based inhalational anesthesia. There was a significant association between TIVA and improved survival. We found that TIVA can improve

Table 2 Univariate associations with survival

\begin{tabular}{|c|c|c|c|c|c|c|}
\hline \multirow[t]{2}{*}{ Factor } & \multicolumn{3}{|c|}{ Overall patients } & \multicolumn{3}{|c|}{ Matched patients } \\
\hline & $P$-value & HR & $95 \% \mathrm{Cl}$ & $P$-value & HR & $95 \% \mathrm{Cl}$ \\
\hline $\begin{array}{l}\text { Blood transfusion } \\
\text { (yes vs no) }\end{array}$ & 0.027 & 1.18 & $1.02-1.37$ & $<0.001$ & 1.40 & $1.17-1.67$ \\
\hline $\begin{array}{l}\text { Cancer stage } \\
\text { (lower vs higher) }\end{array}$ & $<0.001$ & 0.64 & $0.57-0.72$ & $<0.00$ I & 0.74 & $0.64-0.86$ \\
\hline $\begin{array}{l}\text { Degree of differentiation } \\
\text { (lower vs higher) }\end{array}$ & $<0.00 \mathrm{I}$ & 1.20 & I.07-1.35 & $<0.00 \mathrm{I}$ & 1.28 & I.II-I.47 \\
\hline Chemotherapy (yes vs no) & 0.062 & 0.90 & $0.80-1.01$ & 0.191 & 0.91 & $0.79-1.05$ \\
\hline Group (TIVA vs INHA) & $<0.00$ I & 0.63 & $0.56-0.70$ & $<0.00$ I & 0.67 & $0.58-0.77$ \\
\hline Age ( $<60$ years vs $\geq 60$ years) & 0.883 & 0.99 & $0.88-1.11$ & 0.858 & 1.01 & $0.88-1.17$ \\
\hline
\end{tabular}

Abbreviations: $\mathrm{Cl}$, confidence interval; $\mathrm{HR}$, hazard ratio; INHA, inhalational anesthesia; TIVA, total intravenous anesthesia. 
Table 3 Multivariate associations with survival

\begin{tabular}{|c|c|c|c|c|c|c|}
\hline \multirow[t]{2}{*}{ Factor } & \multicolumn{3}{|c|}{ Overall patients } & \multicolumn{3}{|c|}{ Matched patients } \\
\hline & $P$-value & HR & $95 \% \mathrm{Cl}$ & $P$-value & HR & $95 \% \mathrm{CI}$ \\
\hline $\begin{array}{l}\text { Blood transfusion } \\
\text { (yes vs no) }\end{array}$ & 0.002 & 1.26 & I.09-1.47 & $<0.001$ & 1.42 & $1.18-1.70$ \\
\hline $\begin{array}{l}\text { Clinical stage } \\
\text { (lower vs higher) }\end{array}$ & $<0.001$ & 0.62 & $0.55-0.70$ & $<0.001$ & 0.72 & $0.62-0.84$ \\
\hline $\begin{array}{l}\text { Degree of differentiation } \\
\text { (lower vs higher) }\end{array}$ & $<0.001$ & 1.17 & $|.04-| .3 \mid$ & $<0.001$ & 1.23 & I.07-1.42 \\
\hline Group (TIVA vs INHA) & $<0.001$ & 0.61 & $0.55-0.69$ & $<0.001$ & 0.65 & $0.56-0.75$ \\
\hline
\end{tabular}

Abbreviations: $\mathrm{Cl}$, confidence interval; HR, hazard ratio; INHA, inhalational anesthesia; TIVA, total intravenous anesthesia.

the outcome of patients with gastric cancer, which was consistent with a recent study, and it demonstrated that the patients receiving TIVA anesthesia had better survival compared with those receiving inhalational anesthesia. ${ }^{23}$ Other variables associated with survival in multivariate analysis included age, cancer stage, degree of differentiation, and blood transfusion. Chemotherapy and radiation therapy were not associated with a better outcome. We identified associations between cancer stage, degree of differentiation, blood transfusion, and overall survival after gastric cancer resection. These findings were consistent with those of prior observational studies that evaluated other types of cancers, such as breast ${ }^{15,24}$ and colorectal cancer, ${ }^{25}$ and showed that these variables reduced the survival of patients after gastric cancer resection. In our study, we focused on the overall survival in patients receiving TIVA or INHA after gastric cancer resection.

The factors promoting metastasis and recurrence of primary tumors after surgery are diverse. Dissemination of tumor cells, drugs in anesthetic and analgesic processes, ${ }^{26,27}$ destruction of the extracellular matrix ${ }^{28,29}$ release of vascular endothelial growth factor, ${ }^{30}$ and postoperative immunosuppression ${ }^{31,32}$ have been proposed as involved in metastasis and cancer recurrence. Surgical resection of tumors has been demonstrated to induce both the formation of new metastatic foci and lead to locoregional acceleration of tumor growth. ${ }^{7}$ The immune system, and in particular, the cellular immune response that may protect against the proliferation of cancer cells and play a central part in postoperative clearance of cancer cells, is suppressed at the time of surgery. T lymphocytes and NK cells are two predominant cytotoxic effector cells that are the major components of cell-mediated immune responses. One study showed that major visceral surgery suppressed the capacity of circulating NK cells that play a key role in the defense against tumor cells through the release of interferon (IFN)- $\gamma \cdot{ }^{33}$ Another study demonstrated that T-cell suppression in patients undergoing major abdominal surgery was associated with increased T-regulatory cells and a marked induction of myeloid-derived suppressor cells. ${ }^{34}$ Moreover, surgery induces impaired Th1 functions in humans. Impairment of Th1 responses, normally an essential step in specific
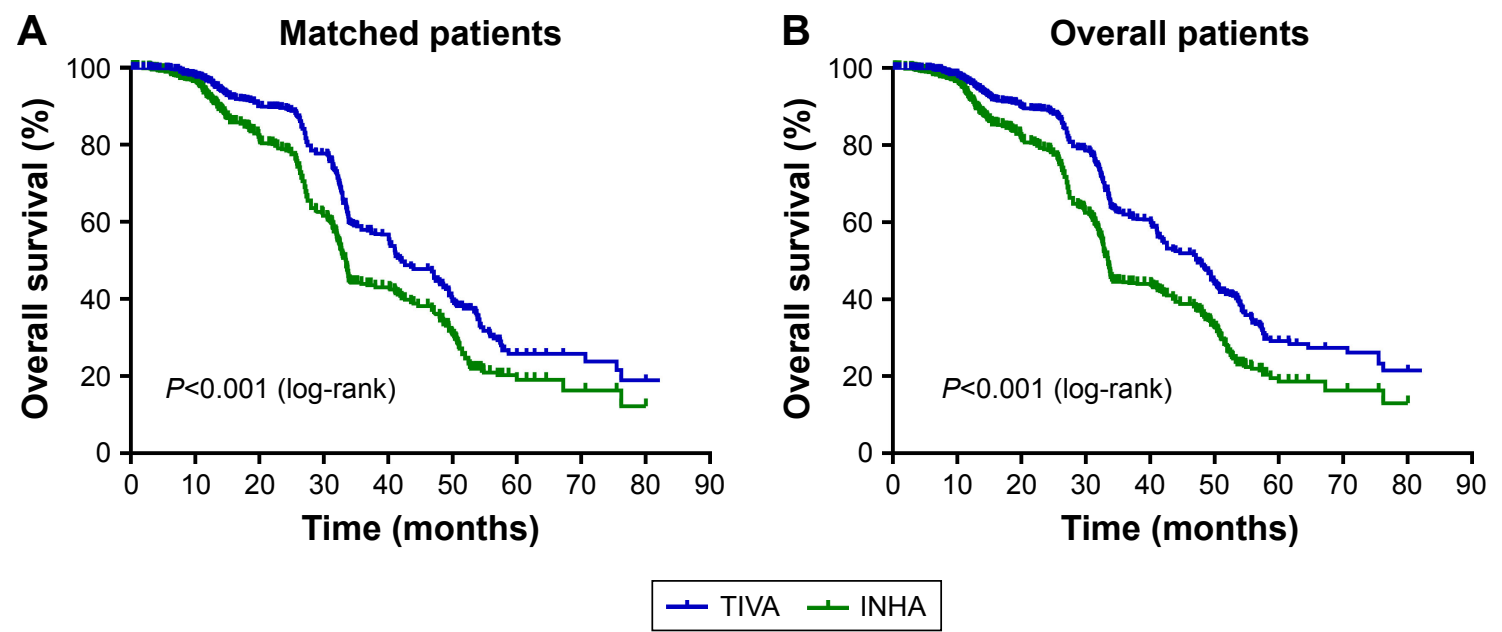

Figure 2 Kaplan-Meier survival curves for patients with TIVA use or INHA use, in matched patients $(\mathbf{A})$ and overall patients (B) (univariate $P<0.00$ I*). Abbreviations: INHA, inhalational anesthesia; TIVA, total intravenous anesthesia. 
cellular immunity and proliferation of cytotoxic $\mathrm{T}$ cells, might also hamper antitumor cytotoxicity. ${ }^{35}$ Additionally, surgery-associated physical injury increased the expression of Th2 cells and brought about impaired cell-mediated immunity. ${ }^{36}$

Propofol has been demonstrated to have protective effects on immune functions and exhibits a good inhibitory effect on tumor recurrence and metastasis. ${ }^{37}$ Some studies have shown that propofol inhibits vascular proliferation and regeneration of esophageal squamous cell carcinoma and metastatic lesions through reduced ERK-VEGF/MMP-9 signaling. ${ }^{38}$ Propofol suppresses tumor growth in a mouse model with preservation of in vitro cytotoxic $\mathrm{T}$ lymphocyte activity. ${ }^{39}$ Propofol also reduces PGE2 production, which is a known mediator of pain and inflammation that inhibits NK cell cytotoxicity through EP2 and EP4 receptors, in vitro. ${ }^{40,41}$ Moreover, another study has shown that propofol could elevate Th1 cytokine secretion and decrease Th2 cytokines, thus protecting against immunosuppression after surgery. ${ }^{42}$ This attribute of propofol compared with volatile agents is consistent with the increased overall survival in the TIVA group in our present study. However, sevoflurane inhibited primary leukocyte integrin lymphocyte function and induced lymphocyte apoptosis through allosteric inhibition of LFA-1, thus promoting tumor recurrence and metastasis. ${ }^{43}$ Patients with low levels of NK cell activity are predisposed to tumor progression. ${ }^{44}$ A recent study has shown that sevoflurane reduced NK cell cytotoxicity through the reduction in CD16 and a failure to increase CD $107 \alpha$ NK receptor expression. ${ }^{45}$ Thus, sevoflurane could influence perioperative immunosuppression through diverse mechanisms that ultimately promote tumor recurrence and metastasis. Our results also showed that sevoflurane-based INHA reduced the survival of the patients after gastric cancer resection.

Ours is the first clinical study to show an association between INHA and a reduction in overall survival for gastric cancer patients who underwent resection, after multivariate analysis. A number of perioperative interventions have been posited to affect cancer cell proliferation at the time of surgery. In particular, data derived from animal and in vitro models have suggested a role for opioids in the promotion of tumor cell survival and of angiogenesis. Although this has led to the theory that regional anesthesia and the consequent minimization of opioid administration may lead to better cancer outcomes, clinical evidence is not conclusive ${ }^{46}$ Other interventions that have been suggested to have a beneficial impact impeding cancer cell growth in the perioperative period include the avoidance of blood transfusion and the use of cyclooxygenase- 2 inhibitors, although again definitive clinical data are lacking. ${ }^{47,48}$

Transfusions might have an effect on patient survival after cancer surgery due to an immunosuppressive effect from such allogeneic material. Several possible mediators may contribute, such as allogeneic mononuclear cells, white-blood-cell-derived soluble mediators, and/or soluble human leukocyte antigen peptides circulating in allogeneic plasma. ${ }^{49,50}$ Our study also found an association between perioperative blood transfusion and an increased hazard ratio for mortality, which is consistent with previous research. This may be due to the fact that blood transfusion can induce suppressed immune functions.

Our study has some unavoidable limitations. One potential limitation was that we did not collect certain clinical data, such as specific drugs administered, detailed surgical techniques, and perioperative opioid use, which induced biases. Another limitation was that we did not measure NK cell activity and markers of immunological function, such as cytokines and cortisol, to detect the mechanisms whereby immune systemic functions were reflected. A future prospective study would be useful to validate our conclusions. Definitive evidence of a causal link would have to come from an ongoing prospective trial.

\section{Conclusion}

In summary, we found that in a cohort of 2,856 patients, the mean survival times in the propofol and sevoflurane groups were 47.4 months and 43.5 months, respectively, revealing a significant association between TIVA use and improved survival in gastric cancer patients who underwent resection. In addition, cancer stage, degree of differentiation, and blood transfusion were also associated with survival in the univariate analysis and multivariable Cox model.

\section{Acknowledgment}

This study was funded by the National Natural Science Foundation of China (grant number 81571885) and the Nn10 Program of Harbin Medical University Cancer Hospital.

\section{Disclosure}

The authors report no conflicts of interest in this work.

\section{References}

1. Liu HT, Wang YW, Xing AY, et al. Prognostic value of microRNA signature in patients with gastric cancers. Sci Rep. 2017;7:42806.

2. Tohme S, Simmons RL, Tsung A. Surgery for cancer: a trigger for metastases. Cancer Res. 2017;77:1548-1552. 
3. Yamaguchi K, Takagi Y, Aoki S, Futamura M, Saji S. Significant detection of circulating cancer cells in the blood by reverse transcriptasepolymerase chain reaction during colorectal cancer resection. Ann Surg. 2000;232:58-65.

4. Rushfeldt C, Sveinbjornsson B, Seljelid R, Smedsrod B. Early events of hepatic metastasis formation in mice: role of Kupffer and NK-cells in natural and interferon-gamma-stimulated defense. $J$ Surg Res. 1999;82:209-215.

5. Oosterling SJ, van der Bij GJ, Meijer GA, et al. Macrophages direct tumour histology and clinical outcome in a colon cancer model. J Pathol. 2005;207:147-155.

6. Horowitz M, Neeman E, Sharon E, Ben-Eliyahu S. Exploiting the critical perioperative period to improve long-term cancer outcomes. Nat Rev Clin Oncol. 2015;12:213-226.

7. Tohme S, Yazdani HO, Al-Khafaji AB, et al. Neutrophil extracellular traps promote the development and progression of liver metastases after surgical stress. Cancer Res. 2016;76:1367-1380.

8. Spolarics Z, Siddiqi M, Siegel JH, et al. Depressed interleukin-12producing activity by monocytes correlates with adverse clinical course and a shift toward Th2-type lymphocyte pattern in severely injured male trauma patients. Crit Care Med. 2003;31:1722-1729.

9. Dai H, Sun T, Liu Z, Zhang J, Zhou M. The imbalance between regulatory and IL-17-secreting CD4(+)T cells in multiple-trauma rat. Injury 2013;44:1521-1527.

10. Choudhry MA, Bland KI, Chaudry IH. Trauma and immune response effect of gender differences. Injury. 2007;38:1382-1391.

11. Zhang Y, Li XF, Wu W, Chen Y. Dynamic changes of circulating T-helper cell subsets following severe thoracic trauma. Int J Clin Exp Med. 2015;8:21106-21113.

12. Snyder GL, Greenberg S. Effect of anaesthetic technique and other perioperative factors on cancer recurrence. Br J Anaesth. 2010;105:106-115.

13. Ecimovic P, Murray D, Doran P, Buggy DJ. Propofol and bupivacaine in breast cancer cell function in vitro - role of the NET1 gene. Anticancer Res. 2014;34:1321-1331.

14. Yang C, Gao J, Yan N, et al. Propofol inhibits the growth and survival of gastric cancer cells in vitro through the upregulation of ING3. Oncol Rep. 2017;37:587-593.

15. Lee JH, Kang SH, Kim Y, Kim HA, Kim BS. Effects of propofolbased total intravenous anesthesia on recurrence and overall survival in patients after modified radical mastectomy: a retrospective study. Korean J Anesthesiol. 2016;69:126-132.

16. Ren XF, Li WZ, Meng FY, Lin CF. Differential effects of propofol and isoflurane on the activation of T-helper cells in lung cancer patients. Anaesthesia. 2010;65:478-482.

17. Song J, Shen Y, Zhang J, Lian Q. Mini profile of potential anticancer properties of propofol. PLoS One. 2014;9:e114440.

18. Xu YJ, Li SY, Cheng Q, et al. Effects of anaesthesia on proliferation, invasion and apoptosis of LoVo colon cancer cells in vitro. Anaesthesia. 2016;71:147-154.

19. Benzonana LL, Perry NJ, Watts HR, et al. Isoflurane, a commonly used volatile anesthetic, enhances renal cancer growth and malignant potential via the hypoxia-inducible factor cellular signaling pathway in vitro. Anesthesiology. 2013;119:593-605.

20. Herling SF, Dreijer B, Wrist Lam G, Thomsen T, Moller AM. Total intravenous anaesthesia versus inhalational anaesthesia for adults undergoing transabdominal robotic assisted laparoscopic surgery. Cochrane Database Syst Rev. 2017;4:CD011387.

21. Zhang T, Fan Y, Liu K, Wang Y. Effects of different general anaesthetic techniques on immune responses in patients undergoing surgery for tongue cancer. Anaesth Intensive Care. 2014;42:220-227.

22. Parsons LS. Reducing Bias in a Propensity Score Matched-Pair Sample Using Greedy Matching Techniques [EB/OL]. Seattle, WA: Ovation Research Group. Available from: http://www2.sas.com/proceedings/ sugi26/p214-26.pdf. Accessed September 22, 2010.

23. Wigmore TJ, Mohammed K, Jhanji S. Long-term survival for patients undergoing volatile versus IV anesthesia for cancer surgery: a retrospective analysis. Anesthesiology. 2016;124:69-79.
24. Woo JH, Baik HJ, Kim CH, et al. Effect of propofol and desflurane on immune cell populations in breast cancer patients: a randomized trial. J Korean Med Sci. 2015;30:1503-1508.

25. Enlund M, Berglund A, Andreasson K, Cicek C, Enlund A, Bergkvist L. The choice of anaesthetic - sevoflurane or propofol - and outcome from cancer surgery: a retrospective analysis. Ups J Med Sci. 2014; 119:251-261.

26. Melamed R, Bar-Yosef S, Shakhar G, Shakhar K, Ben-Eliyahu S. Suppression of natural killer cell activity and promotion of tumor metastasis by ketamine, thiopental, and halothane, but not by propofol: mediating mechanisms and prophylactic measures. Anesth Analg. 2003; 97:1331-1339.

27. Shavit Y, Ben-Eliyahu S, Zeidel A, Beilin B. Effects of fentanyl on natural killer cell activity and on resistance to tumor metastasis in rats. Dose and timing study. Neuroimmunomodulation. 2004;11:255-260.

28. Mokbel K, Choy C, Engledow A. The effect of surgical wounding on tumour development. Eur J Surg Oncol. 2000;26:195.

29. Xu P, Zhang P, Sun Z, Wang Y, Chen J, Miao C. Surgical trauma induces postoperative T-cell dysfunction in lung cancer patients through the programmed death-1 pathway. Cancer Immunol Immunother. 2015;64: $1383-1392$.

30. Lutgendorf SK, Cole S, Costanzo E, et al. Stress-related mediators stimulate vascular endothelial growth factor secretion by two ovarian cancer cell lines. Clin Cancer Res. 2003;9:4514-4521.

31. Shakhar G, Ben-Eliyahu S. Potential prophylactic measures against postoperative immunosuppression: could they reduce recurrence rates in oncological patients? Ann Surg Oncol. 2003;10:972-992.

32. Wang HL, Ning T, Li M, et al. Effect of endostatin on preventing postoperative progression of distant metastasis in a murine lung cancer model. Tumori. 2011;97:787-793.

33. Reinhardt R, Pohlmann S, Kleinertz H, Hepner-Schefczyk M, Paul A, Flohe SB. Invasive surgery impairs the regulatory function of human CD56 bright natural killer cells in response to Staphylococcus aureus. Suppression of interferon-gamma synthesis. PLoS One. 2015;10: e0130155.

34. Albertsmeier M, Quaiser D, von Dossow-Hanfstingl V, Winter H, Faist E, Angele MK. Major surgical trauma differentially affects T-cells and APC. Innate Immun. 2015;21:55-64.

35. Kimura F, Shimizu H, Yoshidome H, Ohtsuka M, Miyazaki M. Immunosuppression following surgical and traumatic injury. Surg Today. 2010;40:793-808.

36. Marik PE, Flemmer M. The immune response to surgery and trauma: implications for treatment. J Trauma Acute Care Surg. 2012;73: 801-808.

37. Liu J, Dong W, Wang T, et al. Effects of etomidate and propofol on immune function in patients with lung adenocarcinoma. Am J Transl Res. 2016;8:5748-5755.

38. Xu YB, Du QH, Zhang MY, Yun P, He CY. Propofol suppresses proliferation, invasion and angiogenesis by down-regulating ERK-VEGF/ MMP-9 signaling in Eca-109 esophageal squamous cell carcinoma cells Eur Rev Med Pharmacol Sci. 2013;17:2486-2494.

39. Kushida A, Inada T, Shingu K. Enhancement of antitumor immunity after propofol treatment in mice. Immunopharmacol Immunotoxicol. 2007; 29:477-486.

40. Inada T, Kubo K, Shingu K. Possible link between cyclooxygenaseinhibiting and antitumor properties of propofol. J Anesth. 2011;25: 569-575.

41. Martinet L, Jean C, Dietrich G, Fournie JJ, Poupot R. PGE2 inhibits natural killer and gamma delta $\mathrm{T}$ cell cytotoxicity triggered by NKR and TCR through a cAMP-mediated PKA type I-dependent signaling. Biochem Pharmacol. 2010;80:838-845.

42. He FY, Feng WZ, Zhong J, Xu W, Shao HY, Zhang YR. Effects of propofol and dexmedetomidine anesthesia on Th1/Th2 of rat spinal cord injury. Eur Rev Med Pharmacol Sci. 2017;21:1355-1361.

43. Yuki K, Astrof NS, Bracken C, Soriano SG, Shimaoka M. Sevoflurane binds and allosterically blocks integrin lymphocyte function-associated antigen-1. Anesthesiology. 2010;113:600-609. 
44. Shakhar G, Blumenfeld B. Glucocorticoid involvement in suppression of NK activity following surgery in rats. J Neuroimmunol. 2003; 138:83-91.

45. Buckley A, McQuaid S, Johnson P, Buggy DJ. Effect of anaesthetic technique on the natural killer cell anti-tumour activity of serum from women undergoing breast cancer surgery: a pilot study. Br J Anaesth. 2014;113(Suppl 1):i56-i62.

46. Biki B, Mascha E, Moriarty DC, Fitzpatrick JM, Sessler DI, Buggy DJ. Anesthetic technique for radical prostatectomy surgery affects cancer recurrence: a retrospective analysis. Anesthesiology. 2008;109: 180-187.

47. Morner ME, Edgren G, Martling A, Gunnarsson U, Egenvall M. Preoperative anaemia and perioperative red blood cell transfusion as prognostic factors for recurrence and mortality in colorectal cancer-a Swedish cohort study. Int J Colorectal Dis. 2017;32:223-232.
48. Roche-Nagle G, Connolly EM, Eng M, Bouchier-Hayes DJ, Harmey JH. Antimetastatic activity of a cyclooxygenase-2 inhibitor. Br J Cancer. 2004;91:359-365.

49. Vamvakas EC, Blajchman MA. Transfusion-related immunomodulation (TRIM): an update. Blood Rev. 2007;21:327-348.

50. Vari A, Gazzanelli S, Cavallaro G, et al. Post-operative nausea and vomiting (PONV) after thyroid surgery: a prospective, randomized study comparing totally intravenous versus inhalational anesthetics. Am Surg. 2010;76:325-328.

\section{Publish your work in this journal}

OncoTargets and Therapy is an international, peer-reviewed, open access journal focusing on the pathological basis of all cancers, potential targets for therapy and treatment protocols employed to improve the management of cancer patients. The journal also focuses on the impact of management programs and new therapeutic agents and protocols on

\section{Dovepress}

patient perspectives such as quality of life, adherence and satisfaction. The manuscript management system is completely online and includes a very quick and fair peer-review system, which is all easy to use. Visit http://www.dovepress.com/testimonials.php to read real quotes from published authors. 